\title{
Preparing displaced adults for the optics/photonics workforce
}

\section{Darrell Hull}

Darrell M. Hull, "Preparing displaced adults for the optics/photonics workforce," Proc. SPIE 3831, Sixth International Conference on Education and Training in Optics and Photonics, (16 June 2000); doi: $10.1117 / 12.388722$

Event: Education and Training in Optics and Photonics (ETOP'99), 1999, Cancun, Mexico 


\title{
PREPARING DISPLACED ADULTS FOR THE OPTICS/PHOTONICS WORKFORCE
}

\author{
Darrell M. Hull \\ Center for Occupational Research and Development (CORD) \\ 601 Lake Air Drive, Waco, TX 76710
}

\begin{abstract}
As the optics/photonics industry continues to grow, the demand for workers is assumed to increase proportionally. Empirical data seem to support this assumption. This increase presents a challenge to optics/photonics educators, since they control and assume responsibility for a key factor in the ability of industry to further expand. At the same time, the U.S. government through the Department of Labor and the Workforce Investment Act has requested that communities enact programs for displaced adults to transition to the workplace. A program of study is provided that would assist adults in making this transition from unemployment to the optics/photonics industry, with the necessary general work skills, occupational optics/photonics skills, and ability to progress on the job with academic foundations in math and science.
\end{abstract}

Keywords: Workforce Education Act, displaced workers or adults, labor, education, training, technician(s)

\section{INTRODUCTION}

The optics/photonics industry is presumed to be growing at a rate similar to that of the semiconductor industry 20 years ago. The applications for the technology abound, and evidence, along with statements from employers, shows that the industry is beginning to take a new shape; where it was once characterized by research and development, that same research has produced results that allow for new kinds of jobs within the industry workforce that are more related to production and manufacturing of photonics systems and components.

For the workforce to meet this new and growing demand from business, additional sources of workers must be identified. With unemployment at a new all-time low in the United States (see figure 1), businesses have become extremely competitive in their efforts to attract and retain qualified workers. In the optics/photonics industry, attempts have been made to identify what the industry desires regarding a qualified worker. In recent years, the industry requirements for workers have evolved along with the change to a production and manufacturing environment. The new optics/photonics workforce employs the former researchers and developers of the technology as the managers of technicians, who must have the capability to fabricate/build, install, maintain, and service integrated electronics and optics systems. To perform these complex tasks, workers need a new set of skills. 


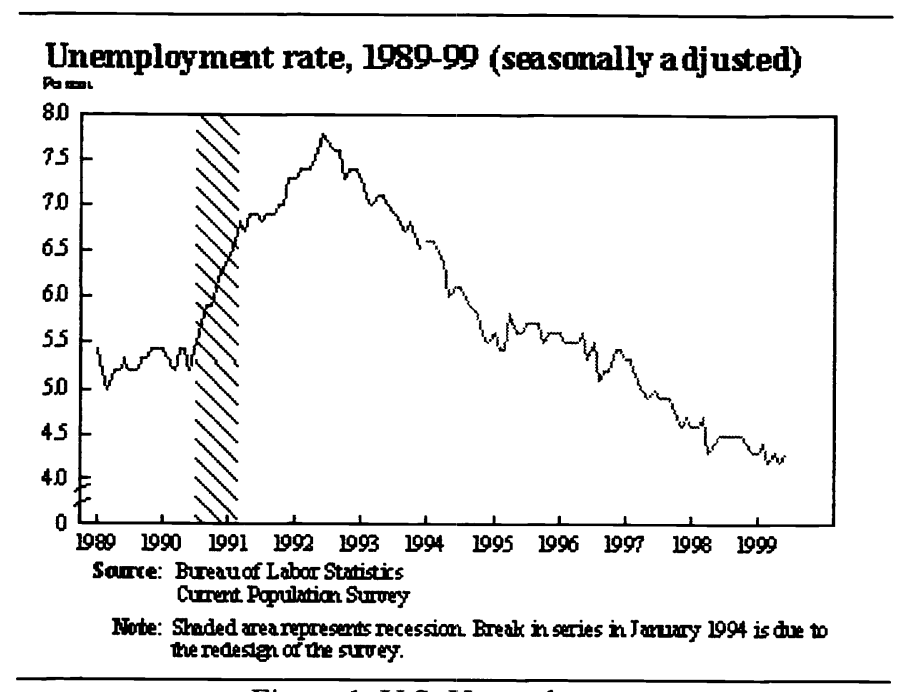

Figure 1. U.S. Unemployment

In 1995, the Center for Occupational Research and Development issued a set of "skill standards" developed under a grant from the U.S. Department of Education (now available on CORD's web site at www.cord.org). These standards began with identification by more than 300 business participants of the critical needs of business and industry. The project then identified in excess of 500 educational knowledge components that must be included in a curriculum of study for these technicians. The time required to impart these educational knowledge components in a coherent program of study would require a certificate or associate degree program in a community college.

It is evident that business and industry cannot wait until students exit such a program; they are hiring the few graduates prior to their program completion. In addition, the community colleges cannot locate enough students to fill their programs due to increased need for workers in other programs of study that currently provide salaries and career opportunities that well exceed those of the optics/photonics industry. This potential shortfall of needed workers has the capability of stifling the industry's growth. Another source of workers must be identified that satisfies the industry demand soon. While this requirement means developing a program that shortcuts the associate degree, it does not mean that the associate degree is not valuable and does not mean that the people who participate in such a shortcut program should not be prepared to enter an associate degree pathway.

Displaced workers are defined as persons aged 20 years and older who have lost or left jobs because their plants or companies have closed or moved, there was insufficient work for them to do, or their positions or shifts have been abolished. In 1998, there were over 2.8 million displaced workers in the United States between the ages of 25 and 54. This supply of workers begs the questions: "What levels of job readiness do these workers possess toward a program that would enable them to participate in the optics/photonics workforce?" and "Would a program that prepares such workers be of benefit?"

Such a program does exist in a basic form, yet the industry and educators are unaware of its existence and ability to solve the present optics/photonics labor shortfall since it has not been reconfigured to produce workers with at least some of the necessary skills identified in the 1995 standard. This program, entitled Transformations 2000, is applicable to most adults who are experienced workers, have basic math and reading skills (up to an 8th grade level), and have interest in technology. With the new STEP curriculum, T2000 can provide specific technical photonics training on a foundation of technical basics and applied academic skills within 18 weeks.

Incentives for such a Transformations program now exist under the Workforce Investment Act of 1998. The act consolidates more than 60 employment, training, and literacy programs under a $\$ 4$ billion program designed to serve adults, displaced workers, and youth. Adults and displaced workers will receive Individual Training Accounts that empower them to choose the training they deem best for their career purposes. The act requires local management of funding through workforce development boards that will replace the current private industry councils. A board is required to establish a "one-stop shop" that provides a single access point for all employment-related and training services. Delivery of Transformations by 
community colleges is perceived to be an enormous opportunity for the optics/photonics workforce since a training provider that is a postsecondary education institution certified under the Higher Education Act and that provides a program leading to a two- or four-year degree or certificate, or that is an entity that carries out an apprenticeship program registered under the National Apprenticeship Act, is automatically eligible to receive funds if it files an appropriate application with the local board. In other words, postsecondary institutions that already have capabilities in optics/photonics can establish eligible programs that will prepare displaced workers to enter the workforce. The Transformations program is already an established method for producing such workers over a shortened time span, yet it allows students to transfer some credit toward an associate degree.

\section{TRANSFORMATIONS 2000}

The first implementation of Transformations took place in 1986 in Copperhill, Tennessee. That was the year that Tennessee Chemical Company (TCC) announced it would close its copper mines in 1987. This meant the mine workers faced probable unemployment in twelve to fifteen months. CORD designed a program that permitted over 90 percent of the workers enrolled in the program to find employment in high technology industries, earning between six and seventeen dollars per hour.

Over the past 13 years, Transformations has been implemented many times in various countries and industries with displaced workers in a redesigned format. The Transformations 2000 program now contains the same three phases contained in the original. The first phase is a pretech phase, lasting 8 weeks with 240 hours of instruction in basic skills for technical employment. The second phase is the technical core, lasting 6 weeks and containing 180 hours of instruction that develops student knowledge and skills for a variety of occupations. The third phase is the technical specialty phase, where students develop specialized skills by focusing on a specific technology area. It is proposed that, with use of the materials being developed by the STEP program, that photonics comprise the majority of the instruction in the technical specialty phase. This final phase lasts 4 weeks and involves 140 hours of instruction.

\begin{tabular}{|c|c|c|c|c|}
\hline $\begin{array}{c}\text { Introduction to } \\
\text { Computers and } \\
\text { Networking } \\
2 \mathrm{Hr} / \mathrm{Day} \\
20 \text { Days } 40 \mathrm{Hr} \\
\end{array}$ & $\begin{array}{l}\text { Graphics for } \\
\text { Technicians } \\
2 \text { Hr/Day } \\
20 \text { Days } 40 \mathrm{Hr}\end{array}$ & \multicolumn{2}{|c|}{$\begin{array}{l}\text { Electricity/Electronics } \\
\begin{array}{c}1.5 \mathrm{Hr} / \mathrm{Day} \\
30 \text { Days } 45 \mathrm{Hr}\end{array}\end{array}$} & \multirow[t]{2}{*}{$\begin{array}{c}\text { Introduction } \\
\text { to } \\
\text { Photonics }\end{array}$} \\
\hline $\begin{array}{c}\text { Workplace } \\
\text { Communication } \\
1 \text { Hr/Day } \\
20 \text { Days } 20 \mathrm{Hr}\end{array}$ & $\begin{array}{l}\text { Mechanical } \\
\text { Devices and } \\
\text { Fluid Power } \\
\text { Systems } \\
1 \text { Hr/Day } 20 \text { Days } 20 \mathrm{Hr}\end{array}$ & \multicolumn{2}{|c|}{$\begin{array}{c}\text { Vacuum Technology } \\
1.5 \mathrm{Hr} / \mathrm{Day} \\
30 \text { Days } 45 \mathrm{Hr}\end{array}$} & \\
\hline \multicolumn{2}{|c|}{ Break $-1 \mathrm{Hr}$} & \multicolumn{2}{|c|}{ Break - $1 \mathrm{Hr}$} & Break - $1 \mathrm{Hr}$ \\
\hline \multicolumn{2}{|c|}{ Self-study $-1 \mathrm{Hr}$} & \multicolumn{2}{|c|}{ Self-study $-1 \mathrm{Hr}$} & Introduction to \\
\hline \multirow{2}{*}{$\begin{array}{c}\text { Applied } \\
\text { Mathematics } \\
3 \mathrm{Hr} / \text { Day } \\
20 \text { Days } 60 \mathrm{Hr}\end{array}$} & \multirow{2}{*}{$\begin{array}{c}\text { Principles of } \\
\text { Technology I } \\
3 \mathrm{Hr} / \text { Day } \\
20 \text { Days } 60 \mathrm{Hr} \\
\end{array}$} & \multirow{2}{*}{$\begin{array}{c}\text { Principles of } \\
\text { Technology II } \\
3 \mathrm{Hr} / \text { Day } \\
20 \text { Days } 60 \mathrm{Hr}\end{array}$} & \multirow{2}{*}{$\begin{array}{c}\text { Foundations } \\
\text { of Quality } \\
3 \mathrm{Hr} / \mathrm{Day} \\
10 \text { Days } 30 \mathrm{Hr} \\
\end{array}$} & $\begin{array}{c}\text { (continued) } \\
3 \text { Hr/Day } 20 \text { Days } 60 \mathrm{Hr}\end{array}$ \\
\hline & & & & $\begin{array}{l}\text { Workplace Readiness } \\
1 \text { Hr/Day } 20 \text { Days } 20 \mathrm{Hr}\end{array}$ \\
\hline \multicolumn{4}{|c|}{$\longleftarrow 8$ Weeks $\longrightarrow$ 6 W V Weeks } & 4 Weeks \\
\hline \multicolumn{2}{|c|}{$\begin{array}{l}\text { Pretech } \\
\text { The first phase provides workers some of the basic skills } \\
\text { needed in technical employment. Pretech includes refresher } \\
\text { courses in math and communication, an introduction to the } \\
\text { use of computers and networking, a basic understanding of } \\
\text { drawings commonly used in technical fields, fundamental } \\
\text { knowledge and skills in working with mechanical devices, } \\
\text { fuld power systems, and a background in physics } \\
\text { mechanical, fluid, electrical, and thermat that is needed } \\
\text { and applied by techniclans. }\end{array}$} & \multicolumn{2}{|c|}{$\begin{array}{l}\text { Tech Core } \\
\text { This phase develops the students' knowledge and } \\
\text { skills that are used in a variety of technical } \\
\text { occupations. This segment includes hands-on } \\
\text { course work in the areas of electricity/electronics, } \\
\text { vacuum technology, and quality/statistical process } \\
\text { control. }\end{array}$} & 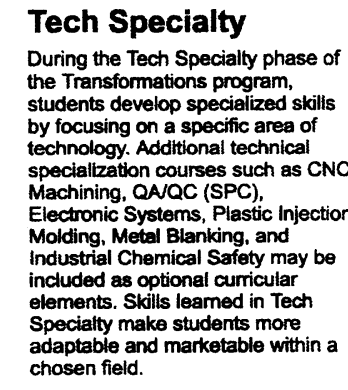 \\
\hline
\end{tabular}

Figure 2. Proposed Photonics Transformations 2000 Program 


\subsection{Program Content}

The Transformations program shown in figure 2 outlines the program content, which progresses smoothly from basic concept to specific applications. It is convenient to view this curriculum in the three major phases shown. The content of the pretechnical and technical core courses is as follows:

1. Introduction to Computers and Networking introduces students to basic keyboarding operation and operating system navigation. Students learn elementary skills for software operation and server connectivity such as web searching and email. The course prepares students for integrated computer work throughout the remainder of the program.

2. Workplace Communication helps students develop improved reading, writing, listening, speaking, problem-solving, visual, and nonverbal skills.

3. Applied Mathematics relates math and technology topics to specific applications, many of which can be demonstrated or experienced by students through tangible exercises.

4. Graphics for Technicians teaches students how to develop and interpret technical sketches and covers the use of line types, multiview drawings, dimensioning, and tolerance practices. The course also includes an introduction to computeraided drafting and its applications.

5. Mechanical Devices and Fluid Systems familiarizes students with different types of drive mechanisms such as belts, chains, and gears, and types of actuators such as mechanical linkages and cams. The fluid portion of the course covers common hydraulic and pneumatic systems, pumps, control valves, flow regulators, cylinders, and motors.

6. Principles of Technology shows relationships between concepts in mechanical, fluid, electrical, and thermal energy systems that are commonly encountered in industrial environments. In this applied form, concepts of physics are taught to students who otherwise might have difficulty understanding them.

7. Electricity/Electronics covers the concepts of voltage, current, resistance, Ohm's law, series and parallel circuits, capacitance, and inductance, and the basic operation of solid-state devices. Hands-on labs include instruction in the use of volt-ohm-milliamp meters, oscilloscopes, signal generators, and other equipment. AC and DC circuits are assembled and tested.

8. Vacuum Technology covers behavior of gases at pressures below atmospheric pressure, mechanical pumps, and subatmospheric gauges, and introduces basic principles of diffusion, turbomolecular, cryogenic, and getter/sputter-ion pumps as well as applications in the technology with leak detection, thin-film deposition, and plasma etching.

9. Foundations of Quality is an inspection methods course. Hands-on labs provide practice in the use of all common inspection instruments used in optics fabrication facilities. Statistical-process control techniques are presented and applied to workplace examples.

The optics/photonics technical specialty is combined with general workplace readiness skills training to prepare workers with the skills needed to work in the optics/photonics industry and also prepare them with the necessary skills to work in any job based on the work of the Secretary's Commission on Achieving Necessary Skills (SCANS), of the Department of Labor.

The optics and photonics materials are being developed under a National Science Foundation project by the University of Connecticut in partnership with CORD. The NSF's Advanced Technological Education initiative provided funding for the first course in a series of 8 that are intended to prepare students in an associate degree program of study. The first course, Introduction to Photonics, contains 10 modules as follows:

1. Nature and Properties of Light (authored by Dr. Linda Vandergriff, SAIC) covers oscillating electric and magnetic fields, wavelength, frequency, velocity of light, the electromagnetic spectrum, blackbody radiation, and particle, ray, and wave concepts. 
2. Light Sources and Safety (authored by Dr. Fred Seeber, Camden County College) covers different nonlaser light sources such as fluorescent, incandescent, LED, and gas discharge. The module also discusses radiometric and photometric terminology and covers all forms of nonionizing radiation safety.

3. Basic Geometrical Optics (authored by Dr. Leno Pedrotti, CORD) covers reflection, refraction, critical angle/total internal reflection, dispersion, minimum angle of deviation, Gaussian and paraxial optics, ray-tracing techniques, mirror equations, thick and thin lenses, and the lensmaker's equation.

4. Basic Physical Optics (authored by Dr. Leno Pedrotti, CORD) covers light rays and phase angle in relationship to wavefronts, electromagnetic wave principles, superposition, Huygen's principle, interference, thin films, diffraction, and diffraction-limited optics.

5. Lasers (authored by Dr. William T. Silfvast, CREOL) covers properties of laser light such as brightness, coherence, beam divergence, and monochromaticity, and basic operations such as pumping, cavities or resonators, and gain. The module also deals with transverse modes, unstable resonators, q-switching, mode locking, and various types of lasers in terms of output, beam properties, and so forth.

6. Optical Detectors and Human Vision (authored by Mr. Jack Ready, Honeywell) covers responsivity, noise equivalent power, quantum efficiency, detectivity, noise (Johnson, 1/f, shot, photon), types of photodetectors (photon, thermal, photoemissive, photoconductive, photomultiplier), spectral response, circuits for photodiodes and detectors, concepts related to human vision, and relative response of a detector circuit as a function of wavelength.

7. Optical Waveguides and Fibers (authored by Dr. Ajoy Ghatak, Indian Institute of Technology) covers the nature of waveguiding, characteristics of fibers such as attenuation and pulse dispersion, calculation of numerical aperture, intermodal dispersion and material dispersion, types of fibers such as single mode, multimode, graded index, and zero dispersion, and fiber loss.

8. Basics of Fiber Optics Telecommunication (authored by Mr. Nick Massa, NSF's Northeast Center for Telecommunications Technology) covers analog versus digital system designs; modulation; wavelengths and their applications; various components including cables, connectors, transmitters, receivers, and repeaters; and tradeoffs in component choices and performance characteristics of installed systems along with testing methods.

9. Photonic Devices for Imaging, Display, and Storage (authored by Dr. Harley Myler, University of Central Florida) covers imaging, pixel, quantization, sampling, and bandwidth; the relationship between resolution and spatial frequency; basic parts of a camera; scanners; computer file storage of images; lossless and lossy image compression schemes; CCDs; vidicons; image intensifiers; CRT displays; and LCD display technology.

10. Basic Principles and Applications of Holography (authored by Dr. T. Jeong, Lake Forest College) teaches transmission holograms, reflection holograms, holographic interferometry, computer-generated holograms, two-source interference, redundancy, dynamic range, noise, beam ratio, multiple scenes, white-light reflection holograms, contouring, thin holograms, and the equipment and facilities necessary to make holograms.

The final course in the program covers workplace readiness skills and addresses SCANs competencies. The course is designed to produce workers with thinking skills who can work with information, work within their resources, ask for help, be accountable for their work, and understand the nature of business from a communication and customer perspective that encourages listening and networking. The course covers interviewing/job-seeking skills, dealing with conflict, team building, presenting information, negotiation skills, meetings, and speaking in public.

\subsection{Curriculum Currency}

The technical specialty area of photonics is subject to problems of currency due to changes in the field with new and emerging technologies. To maintain currency of the materials, the entire STEP curriculum will be subjected to a "curriculum 
morphing" process. Curriculum morphing is a process that allows educators and business and industry participants to suggest technical changes to the curriculum with a structured review of the changes by the authors of the individual modules. All of this happens electronically, and is being tested on CORD's series of laser/electro-optics technology materials.

To view the materials being morphed and to access the new STEP materials this coming October, go to www.cord.org and follow the link to Curriculum Morphing. There, you will find several links and will be able to view the curriculum materials in their entirety. In addition, you will see the morphed changes that have occurred to date. As of the time of this writing, over 300 suggestions have been verified as necessary for changes to the materials from educators and industry participants in the field. As an additional benefit, the project curriculum materials on the web contain hyperlinks to instructional strategies that different instructors in the field use as a part of their everyday classroom and laboratory experiences.

In this way, the Transformations 2000 program in photonics will continually add to the currency of the materials, since more users will be working with the curriculum. The more users who participate, the higher the likelihood of suggestions for changes, and the more up-to-date the materials will be.

\subsection{Program Organization and Delivery}

The Transformations 2000 program content is designed to provide participants with essential information that is useful in a variety of employment situations. However, the manner in which the program is operated and delivered to the students shares equal importance with the content. The success of the Transformations 2000 curriculum with people who performed poorly in their previous educational experiences seems to indicate that attention to factors beyond content enhances the program's effectiveness significantly.

In 1989, the Transformations curriculum was pilot tested at Lorain County Community College, Dayton, Ohio, with four groups of 25 people. Most of the participants in these pilot programs had a high incidence of negative educational experience from the past. Most had been average or below-average performers in traditional classrooms and consequently had developed expectations of failure. In the Transformations programs, however, these people had an overall retention rate of 85 percent. Placement approached 100 percent.

The Transformations program is designed to address the needs of participants in ways that maximize effectiveness and enhance their ability to apply the content in a job setting. Program characteristics addressing this goal include:

1. Hands-on learning. In the Transformations 2000 program, the goal is to relate every concept to specific applications that can be physically experienced. Hands-on application of concepts is accomplished simultaneously or within a very short time following the explanation of those concepts in a classroom setting. Focus on applications enhances the relevance of topics, thereby leading to a higher level of student interest and motivation.

2. Applications orientation. Although participants were not tested on their learning or cognitive styles, it is evident by observation that Transformations 2000 participants respond positively to concrete, active, and participative forms of learning. While students who are strong in the logical and abstract forms of intelligence are able to deal with temporal and spatial separation between theory and application, the majority of learners are better served by immediate reinforcement through tactical, visual, auditory, and kinesthetic reinforcement. ${ }^{1}$

3. Team learning (cooperative learning). Various exercises used in the training require students to work in teams or in small groups. Sharing information and assisting one another are openly discouraged in most traditional classroom settings, but are encouraged in the Transformations 2000 program. The benefits of this approach are many. The students learn from one another, assist one another in clarifying areas of confusion, and develop the skills needed to work together in groups or teams. Studies of industry needs and reactions from advisory groups and industry supervisors indicate that

\footnotetext{
${ }^{1}$ Ronald R. Schmeck, Learning Strategies and Learning Styles (New York: Plenum Press), 1988; and Corrine O'Connor Cody, "Learning Styles including Hemispheric Dominance-A Comparative Study of Average, Gifted and Highly Gifted Students in Grade 5" (Ph.D. diss. University of Michigan, 1983.)
} 
lack of these skills is one of the great weaknesses of the American workforce. In fact, many of the skills and abilities valued in traditional educational settings do not appear to coincide with those skills valued by employers. ${ }^{2}$

Cooperative or team learning can be effective even when the participants do not understand the material at the beginning of the process. In fact, learning that results from joint discovery of new information may be far more effective than learning acquired through conventional means. In addition, most older workers have areas of expertise of which they are not fully aware. Being able to share that information increases their confidence and sense of self-worth. For this reason, efforts were made in the pilot programs to provide opportunities for each participant to share personal knowledge or experience with others in the group.

4. Encouragement of cooperation rather than competition. Traditional educational experiences tend to be individualistic (don't help or ask for help from your neighbor) or even competitive (grading on the curve). Too often the focus is on sorting students into successful or failing categories. Cooperative learning methods, on the other hand, facilitate individual participation and accountability while helping participants develop the ability to work together. Concepts of cooperative learning have been explored in depth by Johnson and Johnson, and the skills and awareness required of instructors and students have been defined. ${ }^{3}$

5. Allowance for differences in learning styles and rates. An environment of mutual support among the participants in the pilot program was strongly encouraged, and a goal of success for all participants was established early and reinforced on a regular basis. As students encountered difficulty or began to fall behind, others in the group were enlisted to encourage and assist them. Extra assistance or tutoring was available on short notice to all participants and was represented as a normal and natural part of the process for everyone. The concept of failure or inadequate performance was shunned both overtly and covertly, and grades were not used. The focus was on assisting everyone to move toward reasonable goals, with little issue made of variations in the time or effort required to achieve these goals.

6. Consideration of personal issues affecting students. The pilot programs focused considerable attention on the emotional and interpersonal needs of the students. Whenever it appeared that anger or frustration was beginning to affect students, interactive focus and ventilation groups were used to provide for processing and diffusing tensions. Not only was individual counseling assistance readily available, but personal and family problems were also recognized as affecting the educational experience and were addressed openly.

The extensive involvement of group interaction (seven hours a day for a period of eighteen weeks) resulted in many friendships and other forms of mutual support among the students. When they were provided with the opportunities for conflict resolution and stress relief, the groups developed a strong rapport and high degree of mutual support. Unlike traditional classrooms, where students may feel alone and in competition with others in the class, members of these groups built a network of support to assist one another in the program.

A side benefit of the overall approach taken by the Transformations 2000 program was improved communication skills for the students. Communication is a difficult area to teach and to learn, since it involves higher-order thinking and analytical skills. But cooperative learning, focus groups, and interchange of personal knowledge all involve practice in effective communication. Therefore, the participants were provided opportunities to practice communication in meaningful ways that could be reinforced by celebrating and rewarding individual contributions.

\section{THE WORKFORCE INVESTMENT ACT}

The Workforce Investment Act of 1998 has one important aspect as its focus - meeting the needs of businesses for skilled workers and the training, education, and employment needs of individuals. Key components of the act will enable customers to easily access the information and services they need through the "one-stop" system, empower adults to obtain the training they find most appropriate through individual training accounts, and ensure that all state and local programs meet customer

\footnotetext{
${ }^{2}$ Paul E. Baron, Skills Employers Need-Time to Measure Them? (Princeton, NJ: Policy Information Center, Educational Testing Center, 1990).

${ }^{3}$ D.W. Johnson and R. Johnson, Learning Together and Alone: Cooperative and Individualistic Learning, 2 nd ed.

(Englewood Cliffs, NJ: Prentice-Hall, 1987).
} 
expectations. The "one stop" concept provides access to a wide array of job training, education, and employment services at a single neighborhood location. At this time, over 800 centers are already in operation across the United States.

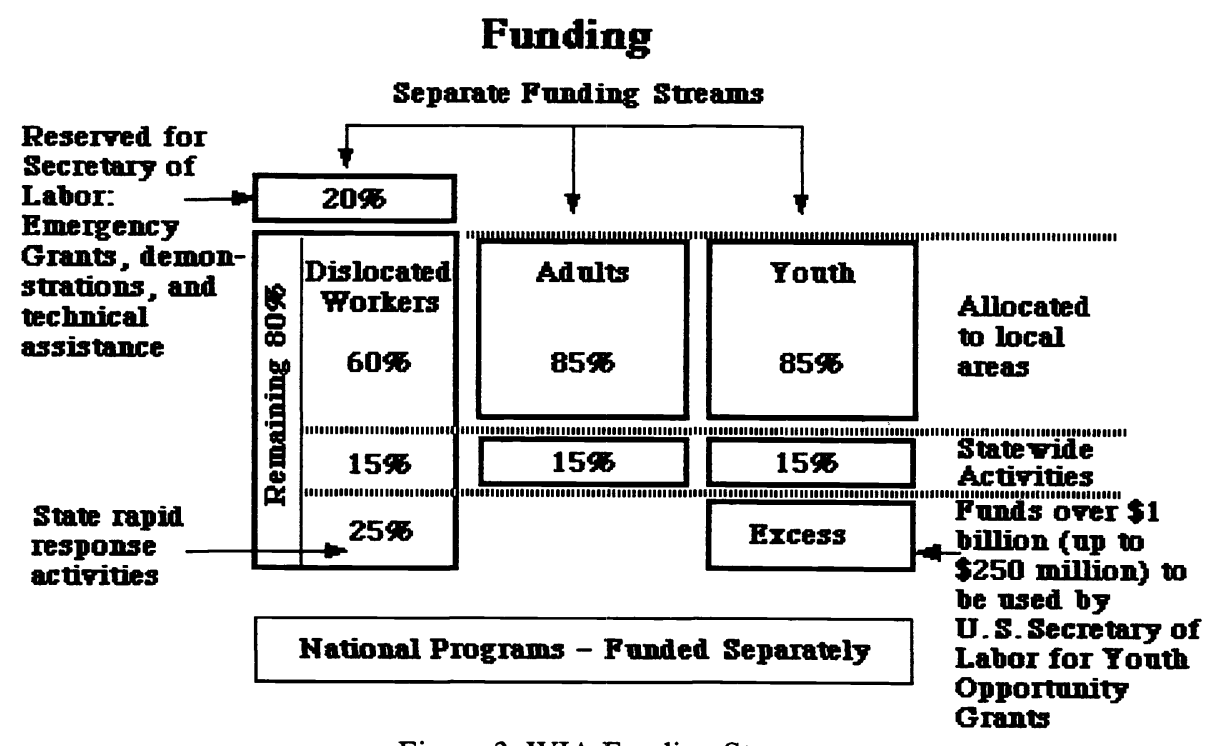

Figure 3. WIA Funding Streams

The Workforce Investment Act authorizes three funding streams: adults, displaced workers, and youth. Eighty-five percent of adult and youth funds will be allocated to local areas; the remainder will be reserved for statewide activities. For youth, funds appropriated in excess of $\$ 1$ billion (up to $\$ 250$ million) will be used by the U.S. Department of Labor to fund Youth Opportunity grants. For displaced workers, 20 percent will reserved by the Secretary of Labor for national emergency grants, displaced worker demonstration efforts, and technical assistance. Of the remaining 80 percent, 60 percent will be allocated to local areas. This 60 percent is the amount of funding being distributed that would support a Transformations 2000 program for a local area, provided that the technical expertise is in place and business and industry indicate a need for such a program.

It is likely that the Workforce Investment Act could provide local funding distributed by the local workforce investment board to support such a program at no cost to employers. In addition, a training provider that is a postsecondary education institution certified under the Higher Education Act and provides a program leading to a two- or four-year degree or certificate, or that is an entity that carries out an apprenticeship program registered under the National Apprenticeship Act, is automatically eligible to receive funds if it files an appropriate application with the local board. This eligibility requirement could open the door for many colleges and universities to satisfy the perceived need for technicians, and, at the same time, displaced workers would have the opportunity to earn a good wage in a growing industry with real career possibilities-A real win/win for the local economy, educational institutions, employers and employees - not to mention the satisfaction on the part of the government for providing a legislated program that meets the needs of so many.

The Department of Labor authorized nine states to begin implementing their state Title I Workforce Investment Act and Wagner-Peyser Act plans on July 1, 1999. Letters containing guidance on how states could move forward were sent to the nine states on June 30, giving them the green light to transition to the Workforce Investment Act (WIA), consistent with the time lines set forth in their plans. The nine states include: Vermont, New Jersey, Kentucky, Florida, Wisconsin, Indiana, Texas, Louisiana and Utah. The remaining states will begin service delivery on July 1, 2000.

\section{SUMMARY}

In the preparation of new or dislocated workers, it is important to remember that the subjects are not inanimate objects, but rather members of the human race with the same wants, needs, and desires as anyone else. For this reason and others of a more pragmatic and economical nature, it makes sense to consider the structure of programs such as Transformations 2000 with an educational focus - a focus on preparing workers with solid foundations in academics that will permit them to pursue careers simply because they have the ability to think and understand the complex processes that occur every day on the job. 


\section{Rethinking the Structure of Career and Technical Education}

BEFORE

Workers Whose Jobs

May Become Obsolete

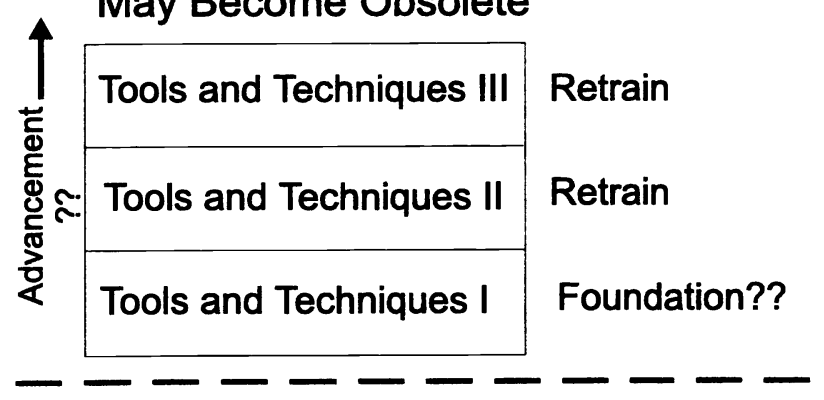

- Voc-ed began with tools and techniques

- CBE meant "teaching the task"

- Craft workers were the skilled tool holders

- Hopefully, the tools and techniques didn't change very quickly

- Workers couldn't adapt to changes of tools and techniques-required retraining

- Foundation lacking for advanced training

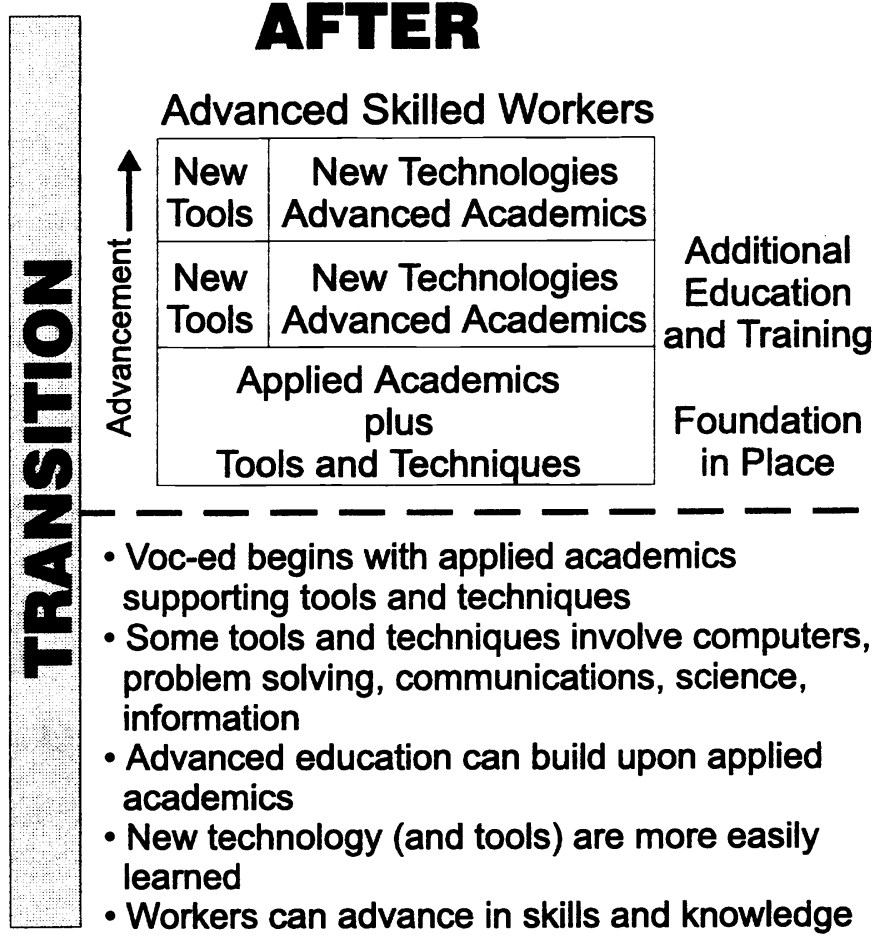

Figure 4. Educational Focus of Today's Career and Technical Education

The face of adult training and workforce education prior to 1985 is pictured on the left side of figure 4 . In retrospect, the approach was simply for satisfaction of short-term needs, primarily because the short-term problems could be solved very quickly. However, with intensive work over 18 weeks, the Transformations 2000 program has demonstrated that it is possible to provide solid academic foundations - foundations that have permitted many students to pursue postsecondary degrees with success. These are the workers who are capable of solving real problems in the optics/photonics workforce. 